\title{
Effect of inhibition of MEK pathway on 5-aza-deoxycytidine-suppressed pancreatic cancer cell proliferation
}

\author{
X. Wang ${ }^{1}$, H. Wang ${ }^{1}$, N. Jiang ${ }^{1}$, W. Lu ${ }^{1}$, X.F. Zhang ${ }^{1}$ and J.Y. Fang ${ }^{2}$ \\ ${ }^{1}$ Department of Gastroenterology Medicine, First People's Hospital of Hangzhou, \\ Hangzhou Medical School, Nanjing University, Hangzhou, Zhejiang, China \\ ${ }^{2}$ Shanghai Institute of Digestive Disease, Renji Hospital, School of Medicine, \\ Shanghai Jiao-Tong University, Shanghai, Shanghai, China \\ Corresponding author: J.Y. Fang \\ E-mail: jingyuanfangcn@126.com
}

Genet. Mol. Res. 12 (4): 5560-5573 (2013)

Received October 24, 2012

Accepted April 5, 2013

Published November 18, 2013

DOI http://dx.doi.org/10.4238/2013.November.18.6

\begin{abstract}
Pancreatic adenocarcinoma is a lethal disease because it is inoperable at the time of diagnosis. Therefore, the search for new therapeutic approaches is critical. The abnormal expression of the mitogen-activated protein kinase/extracellular signal-regulated kinase (MEK) pathway and alteration in epigenetic modification (DNA methylation and acetylation of histones) is a common feature in the majority of human pancreatic adenocarcinomas. Because DNA methyltransferase levels are regulated by the MEK pathway, we examined the effects of an MEK inhibitor, PD98059, on the action of DNA methyltransferase inhibitor 5-aza-2'-deoxycytidine (5-aza-dC), the epigenetic agent in the pancreatic cell line CFPAC1. Our results showed that PD98059 significantly potentiated the capability of 5-aza$\mathrm{dC}$ to induce a cessation of cell proliferation concomitant with cell cycle arrest. We also observed an increase in tumor suppressor gene expression associated with the efficacy of treatment with PD98059 and 5-aza-dC. Further studies explored the molecular mechanisms by which
\end{abstract}


5-aza-dC induced the expression of $\mathrm{p} 21^{\mathrm{WAF} 1}$. We found that 5-aza-dC induced acetylation of histone $\mathrm{H} 3$ on the $\mathrm{p} 21^{\mathrm{WAF} 1}$ gene promoter and demethylation status on the $\mathrm{p} 21^{\mathrm{WAF} 1}$ gene promoter region. These effects were strikingly enhanced by the concomitant blockade of the MEK pathway. Furthermore, knockdown of $\mathrm{p} 21^{\mathrm{WAF} 1}$ by small interfering RNA rescued human pancreatic cancer cells from 5 -aza-dC-mediated growth inhibition. Taken together, our results show that the MEK inhibitor enhanced the effects of 5-aza-dC in human pancreatic cancer cells. These results suggest that the MEK signal pathway may be a potential target for pancreatic cancer therapy.

Key words: Pancreatic cancer cell; MEK pathway; DNA methylation; Histone $\mathrm{H} 3$; p21 ${ }^{\mathrm{WAF} 1}$

\section{INTRODUCTION}

Pancreatic adenocarcinoma is a lethal disease and the 5th most common cause of cancer death worldwide (Pérez-Mancera et al., 2012). Mortality in this disease occurs mainly because the cancer is inoperable at the time of diagnosis and has a striking resistance to conventional treatments (Rittenhouse et al., 2011). The molecular basis of this aggressive clinical behavior remains to be completely elucidated. Epigenetic modifications, such as DNA methylation and acetylation and methylation of histones, modulate chromatin structure and regulate gene expression (Lomberk et al., 2008). Alteration in methylation status has been recognized as an epigenetic mechanism of selection during tumorigenesis in pancreatic cancer, and a correlation between methylation patterns of pancreatic adenocarcinomas and their clinicopathological features has been suggested (Omura and Goggins, 2009). In addition, the hypermethylation of multiple specific genes appears to be a way for the tumor to silence key genes, such as retinoblastoma protein 1, von Hippel-Lindau tumor suppressor, cyclin kinase inhibitors (p15, p16), estrogen receptors, and mutL homolog 1 (Jiao et al., 2007; Cavallari et al., 2009). Epigenetic drugs such as histone deacetylase inhibitors and DNA methyltransferase (DNMT) inhibitors can partially restore the distorted epigenetic picture by removing inactive markers (e.g.; DNA methylation) and inducing active markers (e.g.; histone acetylation), resulting in upregulation of the target genes (Espino et al., 2009).

Of all human malignancies, pancreatic cancer displays the highest frequency (70$90 \%$ ) of somatic activating mutations in RAS genes (mainly KRAS) (Kennedy et al., 2011). RAS-regulated signaling pathways play an important role in the initiation and progression of the disease. The best understood of these pathways is the mitogen-activated protein kinase/ extracellular signal-regulated kinase (ERK) kinase (MEK) pathway, which consists of RafMEK-ERK kinases (Shin-Kang et al., 2011). This pathway has been the subject of intense scrutiny in attempts to understand its fundamental role in cancer cell biology and as a target for therapeutic intervention (Wallace et al., 2005). One of the key roles of the Raf-MEK-ERK pathway in a wide variety of mammalian cell types is the regulation of the cell division cycle. A number of pharmacologic agents, including PD098059, U0126, and CI-1040, have been described that inhibit MEK signaling in mammalian cells. These agents inhibit ERK activity accompanied by G1 cell cycle arrest. Cell cycle progression is regulated by interactions between cyclins and cyclin-dependent kinase inhibitors (CDKIs) (Gysin et al., 2005). CDKIs 
include 2 families: CIP/KIP (e.g., p2 $1^{\mathrm{WAF} 1}$ and $27^{\mathrm{KIP} 1}$ ) and INK4 (e.g., p16 ${ }^{\mathrm{INK} 4 \mathrm{a}}$ ). The increased expression of $\mathrm{p} 21^{\mathrm{WAF} 1}, \mathrm{p} 27^{\mathrm{KIP} 1}$, and $\mathrm{p} 16^{\mathrm{INK} 4 \mathrm{a}}$ may play a crucial role in the growth arrest induced in transformed cells (Gysin et al., 2005; Jiao et al., 2007).

In the present study, we used PD98059 to explore the role of the MEK pathway in the proliferation of human pancreatic cancer-derived cell lines in vitro. PD98059-induced cell G1 cycle arrest was invariably accompanied by the induced expression of CDKI p21 $1^{\text {WAF1 }}$. Blockade of the MEK pathway strikingly potentiated the capability of 5-aza-2'-deoxycytidine (5-aza-dC) to mediate growth arrest of pancreatic cancer cells and upregulate $\mathrm{p} 21^{\mathrm{WAF} 1}$. The upregulation of $\mathrm{p} 21^{\mathrm{WAF} 1}$ may be involved in epigenetic modifications.

\section{MATERIAL AND METHODS}

\section{Cell cultures and treatments}

Pancreatic cancer cell line CFPAC-1 cells (originating from liver metastasis) were cultured at $37^{\circ} \mathrm{C}$ in $5 \% \mathrm{CO}_{2}$ using RPMI 1640 medium (GIBCO, USA) supplemented with $10 \%$ fetal bovine serum, penicillin, streptomycin, and glutamine. Cells were grown to low density $24 \mathrm{~h}$ before treatment and switched to culture medium supplemented with 0-5 $\mu \mathrm{M}$ 5-aza-dC (Sigma, USA) diluted in acidic phosphate-buffered saline (PBS) or 5-75 $\mu \mathrm{M}$ MEK inhibitor PD98059 (Promega, USA) diluted in dimethyl sulfoxide. Cells were treated with PBS or dimethyl sulfoxide as a vehicle control according to the observations of Primeau et al. (2003).

\section{Cell viability assay}

Cells $\left(5 \times 10^{5} / \mathrm{mL}\right)$ were cultured with various concentrations of 5-aza-dC or PD98059 for 1 or 2 days in 96-well plates. After culture, $5 \mathrm{mg} / \mathrm{mL} 3-(4,5$-dimethylthiazol-2-yl)-2,5diphenyltetrazolium bromide reagent (Sigma) was added and incubated for $3 \mathrm{~h}$ at $37^{\circ} \mathrm{C}$ before adding $20 \%$ sodium dodecyl sulfate to dissolve formazan crystals and measuring at the 570 nm wavelength using a Thermomax microplate reader (Molecular Devices, Sunnyvale, CA, USA). All experiments were performed in triplicate and repeated at least 3 times.

\section{Cell cycle profile}

Cell cycle analysis was performed with flow cytometry on cells incubated with various concentrations of either 5-aza-dC or PD98059. Approximately $1 \times 10^{8}$ cells were trypsinized, washed twice with PBS, and fixed in ice-cold ethanol for $1 \mathrm{~h}$. The samples were then concentrated via removal of ethanol and exposure to $1 \%(\mathrm{v} / \mathrm{v})$ Triton X-100 (Sigma) and $100 \mu \mathrm{g} /$ $\mathrm{mL}$ RNase A (Sigma) for $10 \mathrm{~min}$ at $37^{\circ} \mathrm{C}$. Cellular DNA was stained with propidium iodide. Cell cycle distributions were determined using a flow cytometer (Model FACSCALIBAR, USA). Data analysis was performed using the MultiCycle software package (Phoenix, USA).

\section{Inhibition of p21 ${ }^{\mathrm{WAF} 1}$ using small interfering RNA (siRNA)}

Control siRNA and siRNA against $\mathrm{p} 21^{\mathrm{WAF} 1}$ were purchased from Sigma. Briefly, CFPAC-1 cells were seeded in 12-well plates in medium containing $10 \%$ serum at a density that 
would allow cells to reach 50\% confluence on the day of transfection. The transient transfection was performed using $100 \mathrm{nM}$ siRNA duplex and then complexed with transfection reagent in serum- and antibiotic-free culture fluid for $5 \mathrm{~h}$ at $37^{\circ} \mathrm{C}$. A day after the transfection, the medium was replaced with normal growth medium, and $1 \mu \mathrm{M}$ 5-aza-dC or $25 \mu \mathrm{M}$ PD98059 was added for another $48 \mathrm{~h}$ of incubation. All experiments were repeated at least 3 times. The transfection efficiency was determined with fluorescein-conjugated nonspecific siRNA-transfected cells using a fluorescence microscope (Olympus, Japan). Subsequently, the cells were prepared for protein extraction and fluorescence-activated cell sorting analysis. Cells were incubated for $5 \mathrm{~min}$ at room temperature with lysis buffer $\left(\mathrm{K}_{2} \mathrm{HPO}_{4}\right.$, Triton), and lysates were assayed for luciferase activity. Luciferase activity was quantitated with luciferase assays (Promega, USA) using a luminometer.

\section{RNA extraction and real-time polymerase chain reaction (PCR)}

Total RNA was extracted using TRIZOL (Gibco, USA) according to the manufacturer protocol. Real-time PCR was carried out to measure the levels of p2 $1^{\mathrm{WAF} 1}$ using SYBR Green PCR Master Mix (Applied Biosystems, Warrington, UK) as described. The primer sequences were as follows: p2 $1^{\text {WAF1 }}$ forward, 5'-CTGGAGACTCTCAGGGTCGAA-3', reverse 5'-GGATT AGGGCTTCCTCTTGGA-3', p16 ${ }^{\text {INK4a }}$ forward, 5'-CATAGATGCCGCGGAAGGT-3', reverse 5'-CAGAGCCTCTCTGGTTCTTTCAA-3', p27 ${ }^{\mathrm{KIP} 1}$ forward 5'-GCAGTGTCCAGGGATGAG GA-3', reverse 5'-TCTGTTCTGTTGGCCCTTTTGT-3'. Sequences were provided by Shenyou (Shanghai, China). The results were expressed as the ratio of copies of target genes to $\beta$-actin. Relative quantitation data were obtained using the comparative cycle threshold $(\mathrm{Ct})$ method with an ABI PRISM 7700 Sequence Detection System (software version 1.6, ABI, America) according to the manufacturer protocol. The relative changes in gene expression were calculated using the following formula: fold change in gene expression, $2^{-\Delta \Delta \mathrm{Ct}}=2-\left[{ }^{\Delta} \mathrm{Ct}\right.$ (drug-treated samples) $-{ }^{\Delta} \mathrm{Ct}$ (untreated control)], where ${ }^{\Delta} \mathrm{Ct}=\mathrm{Ct}$ (detected genes) - $\mathrm{Ct}(\beta$-actin) and $\mathrm{Ct}$ represents threshold cycle number (Gasparino et al., 2012).

\section{Western blot analysis}

Protein concentration was measured using a Bio-Rad protein assay (Bio-Rad, America) and bovine serum albumin (Sigma) to generate a standard curve. In all, $20 \mathrm{mg}$ proteins was fractionated by electrophoresis in 8 or 15\% sodium dodecyl sulfate-polyacrylamide 1-mm gels and electroblotted onto nitrocellulose membranes. Blocking buffers were either $5 \%$ non-fat dry milk or $1.5 \%$ bovine serum albumin plus $0.05 \%$ Tween 20 in PBS. The primary antibodies were all from Upstate (USA) and included ERK1/2, phospho-ERK1/2 (Cell Signaling Technology, America); p2 ${ }^{\mathrm{WAF} 1}$ (Calbiochem, Germany), p16 ${ }^{\mathrm{INK} 4 \mathrm{a}}, \mathrm{p} 27^{\mathrm{WAF} 1}$ (Santa Cruz Biotechnology, USA); and $\beta$-actin (Sigma). Secondary antibodies (anti-rabbit anti-mouse) conjugated with horseradish peroxidase were from Santa Cruz Biotechnology. Blots were visualized using enhanced chemiluminescence (Amersham Biosciences, UK) and BioMax films (Kodak, Japan). The antibody of $\beta$-actin was used as a control for protein input. The western blot analysis was repeated a minimum of 3 times.

\section{Methylation status of the $\mathrm{p} 21^{\mathrm{WAF} 1}$ promoter region}

Cells were incubated in growth medium supplemented with 0-5 $\mu \mathrm{M} 5$-aza-dC or $25 \mu \mathrm{M}$ 
PD98059 for $48 \mathrm{~h}$. Methylation patterns in the CpG island of these genes were assessed with chemical bisulfite modification as described previously (Almeida et al., 2009). We tested the presence of methylcytosine in the $\mathrm{CpG}$ site inside in the promoter region of $\mathrm{p} 21^{\mathrm{WAF} 1}$ using PCR associated with the methylation-sensitive restriction enzyme HpaII (New England Biolabs, UK). The primers were designed without $\mathrm{CpG}$ dinucleotides to enable both methylated and unmethylated alleles to be amplified (forward primers 5'-GAGTGTAGGGTGTAGGGAGATTG-3' and reverse primers 5'-TCTGGCAGGCAAGGATTTAC-3'). The amplification conditions were 25 cycles of $94^{\circ} \mathrm{C}$ for $45 \mathrm{~s}, 60^{\circ} \mathrm{C}$ for $40 \mathrm{~s}$, and $72^{\circ} \mathrm{C}$ for $60 \mathrm{~s}$, with a final extension of $5 \mathrm{~min}$ at $72^{\circ} \mathrm{C}$. The PCR reaction product was directly loaded onto $3 \%$ agarose gels and electrophoresed.

\section{Chromatin immunoprecipitation assay}

CFPAC-1 cells $\left(5 \times 10^{5} / \mathrm{mL}\right)$ were cultured with $0-5 \mu \mathrm{M} 5$-aza-dC or $25 \mu \mathrm{M}$ PD98059 for $24 \mathrm{~h}$. Formaldehyde was added to the cells to a final concentration of $1 \%$ and the cells were incubated at $37^{\circ} \mathrm{C}$ for $10 \mathrm{~min}$. The cells were collected and subjected to a chromatin immunoprecipitation kit (Upstate Biotechnology) according to the manufacturer protocol. Antibodies used in the immunoprecipitations were purchased from Upstate Biotechnology and they were recognized as acetylated histone $\mathrm{H} 3$. Immunoprecipitated DNA was eluted in a total volume of $50 \mu \mathrm{L}$, and $2 \mu \mathrm{L}$ were used for PCR. The primers for the $\mathrm{p} 21^{\mathrm{WAF} 1}$ promoter were as follows: forward, 5'-CGTGGTGGTGGTGAGCTAGA-3', reverse, 5'-CTGTCTGCACCTTCGCTCC T-3'. Real-time PCR was carried out using SYBR Green PCR Master Mix (Applied Biosystems). The amplified DNA was electrophoresed in a $2 \%$ agarose gel and visualized after staining with ethidium bromide. Enrichment was calculated as the ratio between the net intensity of each bound sample divided by the input (cross-linked DNA/protein complexes) and the vehicle control sample divided by the input [(bound/input)/(control/input)].

\section{Statistical analysis}

Each growth inhibition or flow cytometry experiment was repeated 3-4 times and the average data has been presented. Values of growth inhibition studies were expressed as a percentage of untreated controls. The difference between 2 groups under multiple conditions was analyzed with one-way analysis of variance. All data are reported as means \pm standard error. Data were analyzed using StatView, and a P value of $<0.05$ indicated statistically significant difference.

\section{RESULTS}

\section{Effect of blockade of MEK pathway on the growth delay induced by 5-aza-dC treatment}

We examined the growth inhibition response of CFPAC-1 pancreatic cancer cells exposed to either the DNMT inhibitor 5-aza-dC $(0.5,1,3$, and $5 \mu \mathrm{M})$ or the MEK inhibitor $\operatorname{PD} 98059(5,25,50$, and $75 \mu \mathrm{M})$ for 1 or 2 days. Cell growth was significantly inhibited by treatment with $3 \mu \mathrm{M} 5$-aza-dC for $24 \mathrm{~h}$ and $1 \mu \mathrm{M} 5$-aza-dC for $48 \mathrm{~h}$ compared with that in the control cells. We used various concentrations of PD98059 and found that $25 \mu \mathrm{M}$ PD98059 significantly enhanced 5-aza-dC-induced growth inhibition of CFPAC-1 cells, although the 
effect of PD98059 was not dose dependent. PD98059 significantly potentiated the capability of 5-aza-dC to inhibit the proliferation of CFPAC-1 at $48 \mathrm{~h}$ (Figure 1). Therefore, $25 \mu \mathrm{M}$ PD98059 was used for further experiments.

(A)

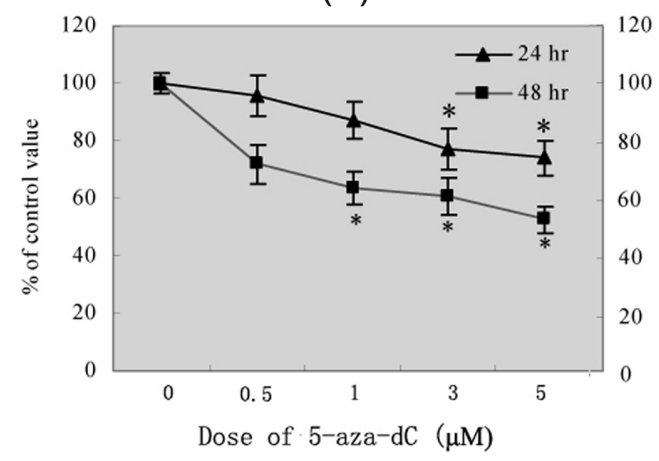

(B)

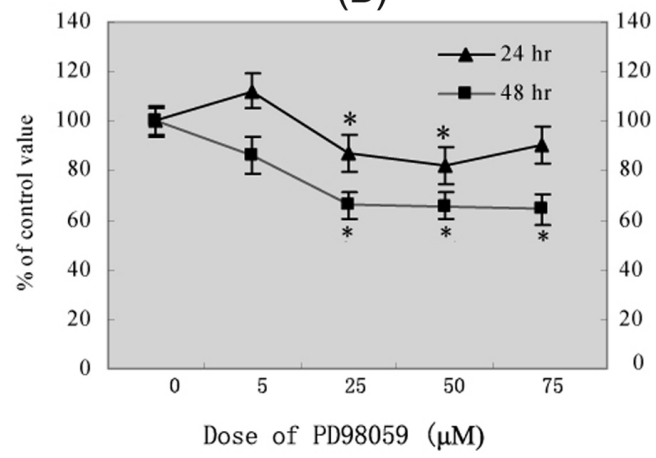

(C)

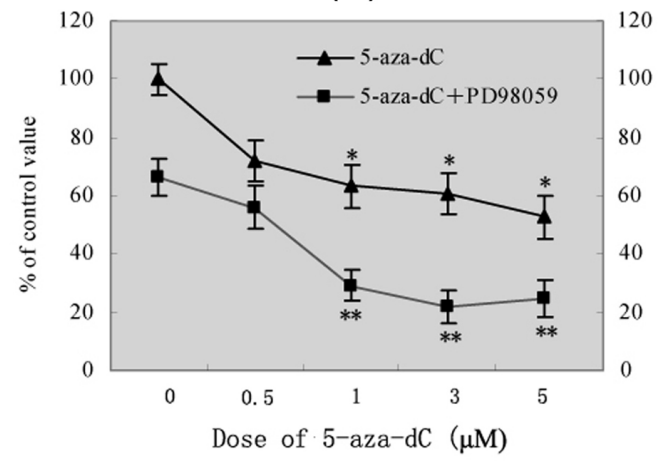

Figure 1. PD98059 potentiates the cell growth suppression induced by 5-aza-deoxycytidine (5-aza-dC) in pancreatic cancer cell line CFPAC-1 cells. CFPAC-1 cells were cultured on a 96-well plate until sub-confluent growth. Viable cells were measured by MTT assay. Two independent time and dose courses were performed in triplicate. Cells were treated with (A) 5-aza-dC (0.5-5 $\mu \mathrm{M})$, or (B) PD98059 (5-75 $\mu \mathrm{M})$, and (C) the combination of both for $48 \mathrm{~h}$. Results are reported as means $\pm \mathrm{SD}$ of three experiments performed in triplicate; and the control cells were treated with phosphatebuffered saline (PBS) and/or dimethyl sulfoxide (DMSO). ${ }^{*} \mathrm{P}<0.05$, $* * \mathrm{P}<0.01$ compared with the control.

\section{Effect of inhibition of MEK pathway on the cell cycle arrest induced by 5-aza-dC treatment}

To study further the influence of the MEK pathway inhibitor on cell cycle arrest induced by 5 -aza-dC, we evaluated the effects of $25 \mu \mathrm{M}$ PD98059 and $1 \mu \mathrm{M} 5$-aza-dC on cell cycle distribution of CFPAC-1 at $48 \mathrm{~h}$. As shown in Table 1, cell cycle analysis using propidium iodide staining showed a delay in the progression, with an increased proportion of cells in the $\mathrm{G} 2 / \mathrm{M}$ and $\mathrm{S}$ phases when cells were exposed to 5-aza-dC alone. These cells accumulated in the G0/G1 phase of the cell cycle when cells were exposed to PD98059 alone. The percentage of cells in the G2/M and S phase of the cell cycle were further increased when cells were 
exposed to PD98059 and 5-aza-dC at these same concentrations compared with that when treated with 5-aza-dC alone or in control cells.

\begin{tabular}{|c|c|c|c|}
\hline Treatment group & G1/G0 & S & G2/M \\
\hline Control & $60.32 \pm 3.71$ & $27.93 \pm 2.81$ & $11.78 \pm 1.54$ \\
\hline 5-aza-dC & $45.54 \pm 3.42 *$ & $32.82 \pm 2.36^{*}$ & $22.67 \pm 2.41 * *$ \\
\hline PD98059 & $69.52 \pm 4.25^{* *}$ & $20.38 \pm 2.41$ & $10.13 \pm 1.24$ \\
\hline 5-aza-dC + PD98059 & $40.81 \pm 3.32 * *$ & $32.23 \pm 2.21 *$ & $25.45 \pm 2.37 * *$ \\
\hline $\mathrm{p} 21^{\mathrm{WAF}} \mathrm{s}$ siRNA + 5-aza-dC & $55.83 \pm 3.64$ & $26.38 \pm 2.53$ & $18.44 \pm 1.56$ \\
\hline p21 $1^{\text {WAF } 1}$ SiRNA + PD98059 & $60.35 \pm 3.83$ & $22.32 \pm 2.87$ & $17.23 \pm 1.98$ \\
\hline p21 $1^{\mathrm{WAF}}$ SiRNA + 5-aza-dC+PD98059 & $52.32 \pm 3.21$ & $30.32 \pm 3.01 *$ & $16.97 \pm 2.03$ \\
\hline
\end{tabular}

\section{Effects of 5-aza-dC and PD98059 with cell cycle-related proteins}

Cells were incubated with the MEK signaling inhibitor, and cell lysates were analyzed for ERK phosphorylation via western blot analysis. Total ERK1/2 protein levels did not decrease in the 5-aza-dC- and PD98059-treated lysates compared with those in the vehicle controls. However, the active form of ERK1/2, phospho-ERK1/2, was decreased in the presence of PD98059. PD08059 treatment decreased the phosphorylation of ERK, but exposure to 5-aza-dC alone failed to decreased levels of phospho-ERK1/2 (Figure 2). Because both 5-aza-dC and the MEK signal pathway can affect the cell cycle, we next explored whether 5-aza-dC or PD98059 modulate the expression of a panel of key components of the cell cycle machinery.

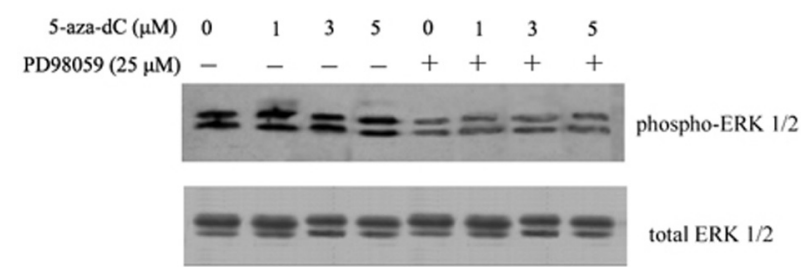

Figure 2. MEK inhibitors downregulate the phosphorylation of ERK. Cells were lysed, and equal amounts of protein were analyzed by Western blot analysis using antibodies against phospho-ERK1/2 or total ERK1/2. The data shown are representative of three replicate experiments. Cells were treated for $48 \mathrm{~h}$ with 5 -aza-deoxycytidine (5-aza-dC) $(0-5 \mu \mathrm{M})$ and/or PD98059 $(25 \mu \mathrm{M})$.

The cell cycle inhibitor $\mathrm{p} 21^{\mathrm{WAF} 1}$ is a well-characterized target of 5-aza-dC and PD98059. We analyzed the expression of $\mathrm{p} 21^{\mathrm{WAF} 1}$ and other CDKIs, $16^{\mathrm{INK} 4 \mathrm{a}}$ and $\mathrm{p} 27^{\mathrm{WAF} 1}$, in CFPAC-1 cells using western blot analysis. 5 -Aza-dC $(1,3$, or $5 \mu \mathrm{M})$ or PD98059 $(25 \mu \mathrm{M})$ alone induced $\mathrm{p} 21^{\mathrm{WAF} 1}$ expression, and the combination of both dramatically increased levels of $\mathrm{p} 21^{\mathrm{WAF} 1}$. Real-time PCR results showed the same tendency (Figure 3). Inactivation of the $\mathrm{p} 16^{\mathrm{INK} 4 \mathrm{a}}$ gene is a frequent event in pancreatic cancer owing to either 
mutation or epigenetic silencing by DNA methylation. The status of $\mathrm{p} 16^{\mathrm{INK} 4 \mathrm{a}}$ in various pancreatic cancer cell lines has already been assayed and has shown promoter hypermethylation. As expected, we found that the expression of $\mathrm{p} 16^{\mathrm{INK4a}}$ protein was upregulated in CFPAC1 when treated with 5-aza-dC, whereas the upregulation of p16 $6^{\mathrm{INK} 4 \mathrm{a}}$ was not significant compared with that after treatment with 5-aza-dC alone or in combination with PD98059. PD98059 slightly induced p16 ${ }^{\mathrm{INK} 4 a}$ expression (see Figure 3). Further experiments confirmed that PD98059 induced expression of $\mathrm{p} 27^{\mathrm{KIP} 1}$, but 5 -aza-dC failed to induce expression of $\mathrm{p} 27^{\mathrm{KIP} 1}$ (see Figure 3 ). These results agree with those of the real-time PCRPCR data YES, Please help to make the revise and show that 5-aza-dC and PD98059 upregulate transcription and translation of the p16 $6^{\mathrm{INK} 4 \mathrm{a}}$ and $\mathrm{p} 27^{\mathrm{WAF} 1}$ genes (see Figure 3B and $\mathrm{C}$ ). Therefore, we hypothesize that $\mathrm{p} 21^{\mathrm{WAF} 1}$ plays an important role in 5-aza-dC- and PD98059-mediated growth inhibition of pancreatic cancer cells.

(A)

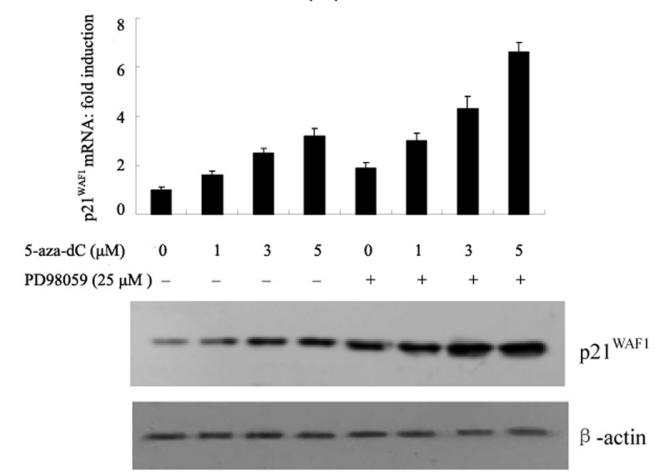

(B)

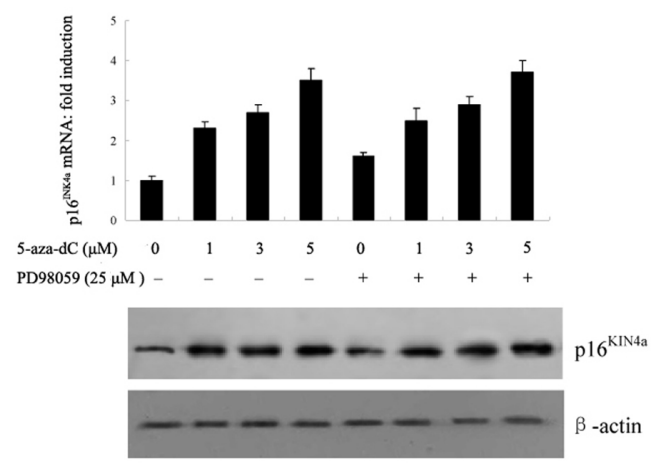

(C)

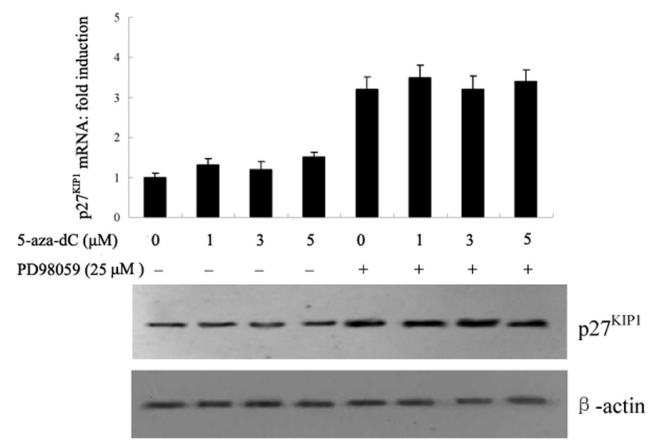

Figure 3. Induction of tumor supressor genes in pancreatic cancer cells after 5-aza-deoxycytidine (5-aza-dC) and PD98059 treatment. CFPAC-1 cell lines were treated for $48 \mathrm{~h}$. The concentration was determined in a separate experiment (Material and Methods). The total RNA was isolated from the various dose treatment. The histogram shows the fold induction of mRNA measured by real-time PCR analysis from the same dish of cells with Western blot. The data are representative of three replicate experiments. A. Induction of $\mathrm{p} 21^{\mathrm{WAF} 1} \mathrm{mRNA}$ and protein, the fold induction was calculated by taking the ratio of $\mathrm{p} 21^{\mathrm{WAF} 1} \mathrm{mRNA}$ abundance in the 5-aza-dC and/or PD98059-treated cells relative to the PBS and/or DMSO control-treated cells. B. Induction of $\mathrm{p} 16^{\mathrm{INK} 4 \mathrm{a}} \mathrm{mRNA}$ and protein expression. C. Induction of $\mathrm{p} 27^{\mathrm{KIPl}} \mathrm{mRNA}$ and protein expression. 


\section{Silencing p21 $^{\text {WAF1 }}$ with siRNA rescue of CFPAC-1 cells from 5-aza-dC-induced growth arrest}

To address the important role of $\mathrm{p} 21^{\mathrm{WAF} 1}$ in 5-aza-dC- and PD98059-mediated growth inhibition of pancreatic cancer cells, we downregulated $\mathrm{p} 21^{\mathrm{WAF} 1}$ via transient transfection with siRNA. After $24 \mathrm{~h}$ of transfection, the cells were exposed to either $1 \mu \mathrm{M} 5$-aza-dC or $25 \mu \mathrm{M}$ PD98059 for $48 \mathrm{~h}$ and subjected to western blot and flow cytometry to quantify the levels of $\mathrm{p} 21^{\mathrm{WAF} 1}$ and cell cycle progression, respectively. The transfection of control siRNA had little or no effect on $\mathrm{p} 21^{\mathrm{WAF} 1}$ expression, whereas $\mathrm{p} 21^{\mathrm{WAF} 1}$ siRNA led to a striking reduction in $\mathrm{p} 21^{\mathrm{WAF} 1}$ expression. The siRNA against $\mathrm{p} 21^{\mathrm{WAF} 1}$ almost completely blocked 5-aza-dC- and PD98059induced expression of $\mathrm{p} 21^{\mathrm{WAF} 1}$ (Figure 4). Depletion of $\mathrm{p} 21^{\mathrm{WAF} 1}$ increased cell viability compared with that observed with control siRNA (see Figure 4). The p $21^{\mathrm{WAF} 1}$ siRNA reduced the percentage of 5-aza-dC-treated cells that were arrested in $\mathrm{G} 2 / \mathrm{M}$ with a concomitant increase in the percentage of cells transiting through $\mathrm{S}$ phase (see Table 1). These results suggested that the induction of $\mathrm{p} 21^{\mathrm{WAF} 1}$ was critical in 5-aza-dC-mediated growth inhibition of pancreatic cancer cells.
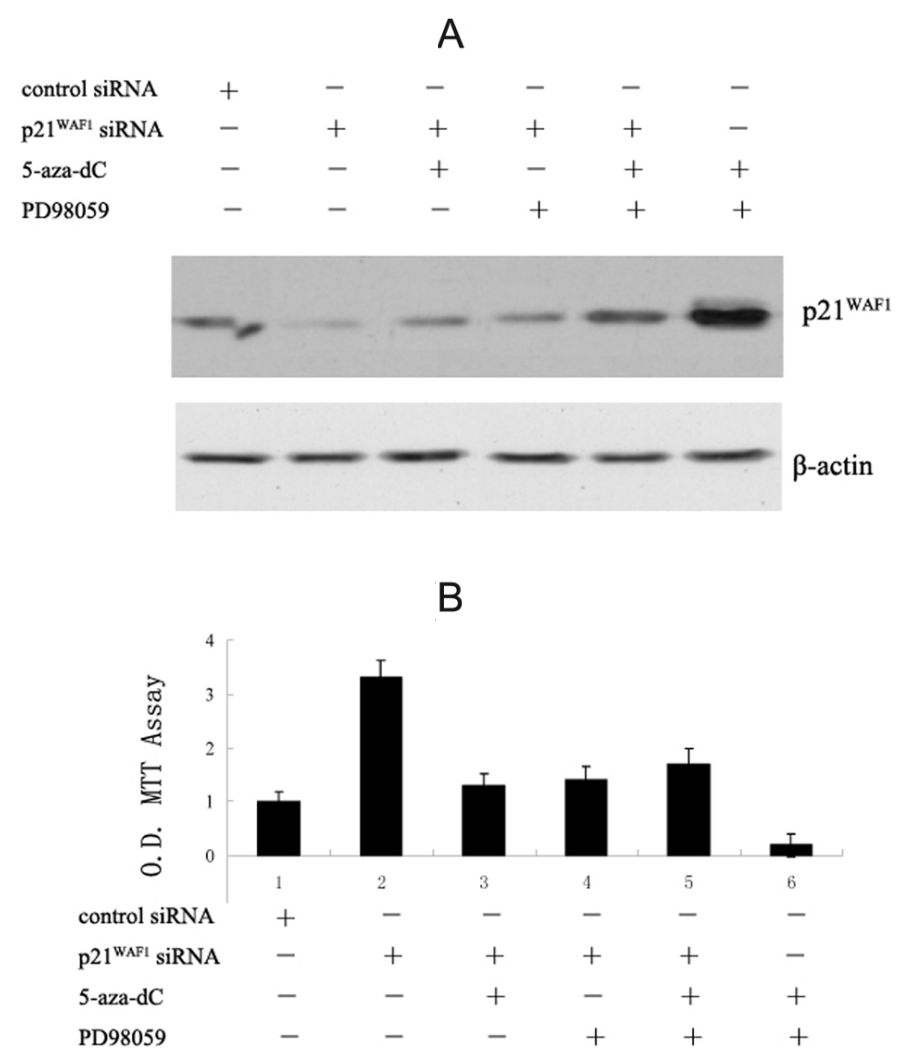

Figure 4. Depletion effect of $\mathrm{p} 21^{\mathrm{WAF} 1}$ by siRNA potentiates the effects of 5-aza-deoxycytidine (5-aza-dC) in CFPAC-1 cells. The cells were transiently transfected either with control or $\mathrm{p} 21^{\mathrm{WAF} 1}$ siRNA. After $24 \mathrm{~h}$, these cells were exposed to either 5-aza-dC $(1 \mu \mathrm{M})$ and/or PD98059 $(25 \mu \mathrm{M})$ for $48 \mathrm{~h}$ and subjected to Western blot. The cell viability was quantified by MTT. A. siRNA almost completely blocked 5-aza-dC-induced expression of p2 ${ }^{\text {WAF1 }}$. B. Cell viability was dramatically restored even expoured to 5-aza-dC. 


\section{Methylation status and acetylation of histone $\mathrm{H3}$ induced by 5 -aza-dC and PD98059}

To investigate the mechanism of the $\mathrm{p} 21^{\mathrm{WAF} 1}$ response to combined 0-5 $\mu \mathrm{M} 5$-aza-dC and $25 \mu \mathrm{M}$ PD98059 exposure for $48 \mathrm{~h}$, we examined the epigenetic alteration of $\mathrm{p} 21^{\mathrm{WAF} 1}$. The promoter region of $\mathrm{p} 21^{\mathrm{WAF} 1}$ contains palindromic sequences recognized by signal transducers and activators of transcription 1 (Chen et al., 2000). We analyzed the status of promoter methylation for $\mathrm{p} 21^{\mathrm{WAF} 1}$ in CFPAC-1 cells by bisulfite-modified PCR of the modified DNA samples. The results are shown in Figure 5. The $\mathrm{CpG}$ island of the $\mathrm{p} 21^{\mathrm{WAFl}}$ promoter was methylated in CFPAC-1, which was reverted by 5 -aza-dC but not by PD98059. These results suggested that 5-aza-dC-induced messenger RNA expression of the $\mathrm{p} 21^{\mathrm{WAF} 1}$ gene might be by a methylation-dependent mechanism. One study has suggested that covalent chromatin changes could regulate the expression of $\mathrm{p} 21^{\mathrm{WAF} 1}$ (Zheng et al., 2006). Chromatin immunoprecipitation analysis was performed using acetylated histone $\mathrm{H} 3$ antibodies as described in the materials and methods. Either 5-aza-dC or PD98059 treatment enriched acetylated histone H3 close to the $\mathrm{p} 21^{\mathrm{WAF} 1}$ transcription start sites in CFPAC-1. The combination of $1 \mu \mathrm{M} 5$-aza-dC and 25 $\mu \mathrm{M}$ PD98059 for $48 \mathrm{~h}$ strikingly induced acetylation of histone $\mathrm{H} 3$ around the $\mathrm{p} 21^{\mathrm{WAF} 1}$ gene (Figure 6) consistent with the results of western blot analysis.

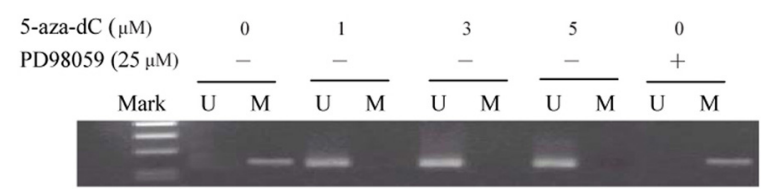

Figure 5. 5-aza-deoxycytidine (5-aza-dC) induced demethylation of the $\mathrm{p} 21^{\mathrm{WAF} 1}$ promoters. Methylation-specific PCR (MSP) was performed on DNA from CFPAC-1 cells with primers designed to specifically detect methylated and unmethylated promoter regions. $U$ = unmethylated-MSP; $M=$ methylated-MSP. The data are representative of three replicate MSP experiments. Cells were treated for $48 \mathrm{~h}$ with 0-5 $\mu \mathrm{M}$ 5-aza-dC and $25 \mu \mathrm{M}$ PD98059.

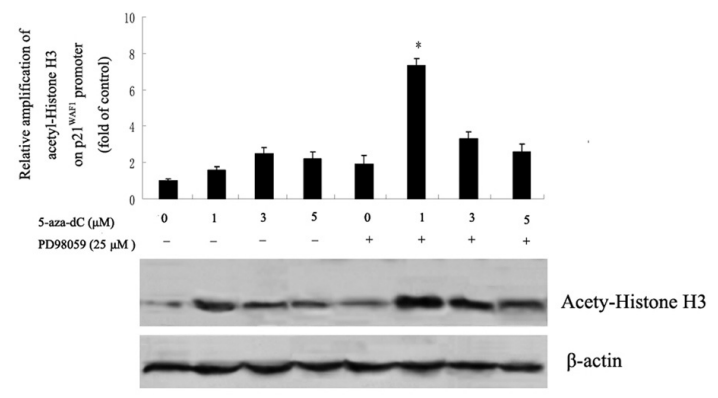

Figure 6. PD98059 enhances 5-aza-deoxycytidine (5-aza-dC)-induced acetylation of histone H3. CFPAC-1 cells were exposed to 5-azadC (1-5 $\mu \mathrm{M})$ and/or PD98059 $(25 \mu \mathrm{M})$. After $48 \mathrm{~h}$, cells were harvested and subjected to Western blot and chromatin immunoprecipitation (ChIP) assay. The Figure is representative of the two experiments performed independently. A. Nuclear extracts were prepared and subjected to Western blot analysis to measure the level of acetyl-histone $\mathrm{H} 3$ and $\beta$-actin. B. Acetylation of histone $\mathrm{H} 3$ in the $\mathrm{p} 21^{\mathrm{WAF} 1}$ promoter was analyzed by ChIP assay. Real-time PCR were employed to quantify acetylated DNA precisely. The amplified sequences were normalized to those from input (the cross-linked DNA/protein complexes which were not immunoprecipitated with anti-acetylated histone $\mathrm{H} 3$ antibody). Results are reported as means $\pm \mathrm{SD}$ of three experiments performed in triplicate; $* \mathrm{P}<0.05$, compared with the control. 


\section{DISCUSSION}

Previous studies have convincingly proven the role of aberrant methylation and histone acetylation in the initiation and progression of several tumor types, including pancreatic adenocarcinoma (Omura and Goggins, 2009; Hong et al., 2012). The MEK pathway plays an important role in the regulation of cell division, and the current study as well as others suggest that an increase of MEK pathway activity may be responsible for the increased DNA methyltransferase enzyme activity and promoter hypermethylation of tumor suppressor genes. Hypermethylation is frequently associated with the silencing of genes, which may represent a selective advantage for growth and survival in the affected cells (Sato et al., 2008; Wang et al., 2009; An et al., 2011). The MEK pathway also affects covalent histone modification such as phosphorylation, acetylation, and methylation in localized promoter regions, which are markers for chromatin packing and transcription (Espino et al., 2009).

Pancreatic adenocarcinoma is characterized clinically by resistance to all current chemotherapy treatment (Takayama et al., 2008). Therefore, the aim of this study was to assess the efficacy of 5-aza-dC treatment in inhibiting cell growth and the effect of PD98059 enhancement of 5-aza-dC sensitization in pancreatic cancer models. We sought to identify the molecular mechanisms behind differential effects by analyzing alterations in tumor suppressor gene expression profiles induced by 5 -aza-dC and PD98059 treatment in cell models.

Several clinical trials of 5-aza-dC administration conducted in diverse tumor types have shown various degrees of efficacy, particularly in solid tumors (Mostovich et al., 2011). Control of cell cycle progression is considered a potentially effective strategy for tumor growth, and the molecular analysis of common malignancies in humans have revealed that cell cycle regulators are frequently mutated (Kennedy et al., 2011). The results of the present study revealed strong inhibition of CFPAC-1 cell proliferation associated with arrest or delay in S or G2/M phase after treatment with 5-aza-dC. The predominantly cytostatic effects of 5-aza-dC have also been observed for other pancreatic cancer cell lines, such as $\mathrm{PaCa} 44$ and Panc-1, although the MiaPaCa2 cell line is relatively unresponsive (Missiaglia et al., 2005). The effects differ among cell lines; therefore, we selected the relatively responsive cell line CFPAC-1 in our study.

Inhibition of MEK/ERK signaling accumulates cells in the G0/G1 phase of the cell cycle (Wallace et al., 2005). For example, sorafenib, a selective inhibitor of B-Raf/MEK kinase, induces accumulation of malignant peripheral nerve sheath tumors and liposarcoma cells in $\mathrm{G} 0 / \mathrm{G} 1$ in association with dephosphorylation of the retinoblastoma protein, which plays an important role in the progression of cells into the S phase of the cell cycle (Ambrosini et al., 2008). Inhibition of MEK by PD98059 also induces G0/G1 cell cycle arrest in CFPAC-1 cells. Interestingly, 5-aza-dC-induced growth inhibition and cell cycle arrest of CFPAC-1 cells were strikingly blunted when the MEK pathway was blocked by PD98059.

The data presented here suggest disruption of the uncontrolled cell cycle progression of these cells. One mechanism for PD98059-induced cell cycle arrest is through induced expression of $\mathrm{p} 21^{\mathrm{WAF} 1}$ and $\mathrm{p} 27^{\mathrm{KIP} 1}$. The mechanism of 5-aza-dC-induced cell cycle arrest is through $\mathrm{p} 16^{\mathrm{INK} 4 \mathrm{a}}$ and $\mathrm{p} 21^{\mathrm{WAF} 1}$, leading to inhibition of cyclin/cyclin-dependent kinase 2 activity. The CDKIs p16 $6^{\mathrm{IN} 4 \mathrm{a}}, \mathrm{p} 21^{\mathrm{WAF} 1}$, and $\mathrm{p} 27^{\mathrm{KIP} 1}$ bind with and inhibit the activity of CDK-cyclin complexes and, thus, regulate both G0/G1 and G2/M arrest transitions (Kim et al., 2007; Pal-Bhadra et al., 2012). The combination of 5-aza-dC and PD98059 induced striking expression of $\mathrm{p} 21^{\mathrm{WAF} 1}$.

Previously published data have suggested that reduced levels of p27 $7^{\mathrm{KIP} 1}$ expression are associated with poor prognosis in certain types of cancer (Culhaci et al., 2005). 5-Aza-dC 
elicited no expression of $\mathrm{p} 27^{\mathrm{KIP} 1}$. Regulation of $\mathrm{p} 27^{\mathrm{KIP} 1}$ expression reportedly involves alterations in gene transcription, control of messenger RNA translation, and posttranslational regulation of protein stability (Missiaglia et al., 2005; Wang et al., 2008). The precise mechanisms underlying these observations are unknown. Consequently, MEK inhibitors may tend to have more of a cytostatic, as opposed to a cytotoxic, effect when used as single agents. However, inhibition of MEK might also prime the pancreatic cancer cell for apoptosis in response to concomitant radiotherapy or chemotherapy.

Previous studies on the effects of 5-aza-dC on gene expression profiles in colon and prostate cancer cell lines have already observed growth inhibition. Furthermore, inhibition of DNMT1 activity using a conditional mutation in a mouse model has shown a similar response at the gene expression profile level, indicating that the activation of this pathway is associated with the specific effect of 5-aza-dC on DNMT1 activity rather than a secondary cytotoxic outcome (Jackson-Grusby et al., 2001). In addition, a recent study has shown that the epigenetic silencing of multiple genes is involved in cellular immortalization, which is then reverted by treatment with 5 -aza-dC, suggesting that this alteration may be associated with an early event in tumorigenesis (Guo et al., 2012). The tumor suppressor genes $\mathrm{p} 16^{\mathrm{INK} 4 \mathrm{a}}$ and $\mathrm{p} 53$, which are critically involved in pancreatic cancer tumorigenesis, are also implicated in the response to 5-aza-dC treatment (Ma et al., 2010; Yu et al., 2012). The analysis of the expression of $\mathrm{p} 16^{\mathrm{INK} 4 \mathrm{a}}$ protein confirmed its upregulation after 5 -aza-dC treatment in CFPAC-1. However, the S and G2/M delay together with results of previous studies that have demonstrated $\mathrm{p} 16^{\text {INK4a }}$-independent growth inhibition of tumor cells induced by 5-aza-dC (Ma et al., 2010), suggesting that its effect is not limited to the re-expression of $\mathrm{p} 16^{\mathrm{INK} 4 \mathrm{a}}$.

Hence, we speculate that upregulation of $\mathrm{p} 21^{\mathrm{WAF} 1}$ may be responsible for cell cycle arrest or delay after treatment with 5-aza-dC and PD98059. Our study and others found hypermethylation of the Sis-inducible element (SIE)-1, SIE-1 site in the $\mathrm{p} 21^{\mathrm{WAF}}$ promoter region in CFPAC1 cell lines, which was partially reverted by 5-aza-dC treatment and coupled with increased $\mathrm{p} 21^{\mathrm{WAF}}$ expression at both the transcriptional and the protein levels (Missiaglia et al., 2005) Although the $\mathrm{p} 21^{\mathrm{WAF} 1}$ protein is frequently responsible for $\mathrm{G} 1$ arrest, substantial evidence supports another role in $\mathrm{S} / \mathrm{G} 2$ transition. $\mathrm{p} 21^{\mathrm{WAF} 1}$ is thought to induce $\mathrm{G} 2$ arrest by interacting with the $\mathrm{Cdc} 2$-cyclinB1 complex together with proliferating cell nuclear antigen (PCNA). Furthermore, $\mathrm{p} 21^{\mathrm{WAF} 1}$ inhibits the interaction of PCNA and DNA polymerase delta, which is essential for DNA replication and repair and consequently inhibits DNA synthesis (Tan and Porter, 2009). Downregulation of DNMT1, which competes with $\mathrm{p} 21^{\mathrm{WAF} 1}$ for the same binding site on PCNA (Chuang et al., 1997; Tan and Porter, 2009), may further enhance the inhibitory effect of $\mathrm{p} 21^{\mathrm{WAF} 1}$ on both DNA synthesis and cell growth.

Other investigators have found that the exposure of colon carcinoma HCT116 cells or NB4 cells to 5-aza-dC induces G2/M cell-cycle arrest - a hallmark of DNA double-strand breaks by monitoring the formation of g-H2AX foci and performing comet assay (Scott et al., 2006). The present study found an interesting biological function of 5-aza-dC using a low dose of 5-aza-dC (1 $\mu \mathrm{M}$ ), which induced acetylation of histone $\mathrm{H} 3$. However, higher doses of this compound potently induced DNA demethylation in CFPAC-1 cells, and PD90859 enhanced the effects of 5-aza-dC through acetylation of histone $\mathrm{H} 3$ on the $\mathrm{p} 21^{\mathrm{WAF} 1}$ promoter region as well as through demethylation of the tumor suppressor gene promoter. Generally, 5-aza-dC is incorporated into DNA during replication, resulting in sequestration of DNMT1 and leading to replication-dependent global demethylation and gene reactivation (Chuang et al., 1997). Thus, 5-aza-dC might have biphasic effects.

Of particular interest, PD98059 enhanced the capability of 5-aza-dC to induce acetylation of histone $\mathrm{H} 3$ and DNA demethylation in CFPAC-1 cells, resulting in marked upregula- 
tion of $\mathrm{p} 21^{\mathrm{WAF} 1}$. We found that inhibition of MEK by PD98059 modestly decreased acetylated histone $\mathrm{H} 3$ in CFPAC-1 cells. The inhibition of histone $\mathrm{H} 3$ acetylation by this MEK inhibitor may cause chromatin relaxation, leading to susceptibility to 5-aza-dC-induced expression of the $\mathrm{p} 21^{\mathrm{WAF} 1}$ gene. Knockdown of $\mathrm{p} 21^{\mathrm{WAF} 1}$ with siRNA protected CFPAC-1 cells from 5-aza$\mathrm{dC}$-induced cell growth delay, suggesting that $\mathrm{p} 21^{\mathrm{WAFl}}$ played a critical role in 5-aza-dC-induced growth inhibition in pancreatic cancer cells. In addition, these observations suggested that marked induction of the acetylated forms of histone $\mathrm{H} 3$ and $\mathrm{p} 21^{\mathrm{WAF} 1}$ after exposure to 5-aza-dC may predict the responsiveness of pancreatic cells to this class of agent.

In a word, 5-aza-dC induced growth arrest and upregulation of $\mathrm{p} 21^{\mathrm{WAF} 1}$ in CFPAC-1 cells via epigenetic mechanisms. Concomitant blockade of MEK signaling potentiated the action of 5-aza-dC in CFPAC-1 cells. The combination of a demethylation agent and a MEK inhibitor may open a new avenue for the treatment of individuals with pancreatic cancer.

\section{Conflicts of interest}

The authors declare no conflicts of interest.

\section{ACKNOWLEDGMENTS}

We thank the Shanghai Institute of Digestive Disease Laboratory for advice, suggestions, and constructive criticism of this work. We are especially grateful to Dr. Jingyuan Fang for advice on the use of $\mathrm{p} 21^{\text {WAF1 }}$ siRNA and for critical appraisal of the manuscript. We thank Weiqi Gu and Hong Yin Zhu for performing real-time and methylation-specific PCR and Ms. Yingchao Wang and Ms. Lingen Li for performing flow cytometry. Research supported by grants from the National Natural Science Fund Projects (\#81001078) and Technology Development Foundation of Hangzhou (\#2008033Q02).

\section{REFERENCES}

Almeida LO, Custódio AC, Pinto GR, Santos MJ, et al. (2009). Polymorphisms and DNA methylation of gene TP53 associated with extra-axial brain tumors. Genet. Mol. Res. 8: 8-18.

Ambrosini G, Cheema HS, Seelman S, Teed A, et al. (2008). Sorafenib inhibits growth and mitogen-activated protein kinase signaling in malignant peripheral nerve sheath cells. Mol. Cancer Ther. 7: 890-896.

An HJ, Lee H and Paik SG (2011). Silencing of BNIP3 results from promoter methylation by DNA methyltransferase 1 induced by the mitogen-activated protein kinase pathway. Mol. Cells 31: 579-583.

Cavallari I, Silic-Benussi M, Rende F, Martines A, et al. (2009). Decreased expression and promoter methylation of the menin tumor suppressor in pancreatic ductal adenocarcinoma. Genes Chromosomes Cancer 48: 383-396.

Chen B, He L, Savell VH, Jenkins JJ, et al. (2000). Inhibition of the interferon-gamma/signal transducers and activators of transcription (STAT) pathway by hypermethylation at a STAT-binding site in the p21WAF1 promoter region. Cancer Res. 60: 3290-3298.

Chuang LS, Ian HI, Koh TW, Ng HH, et al. (1997). Human DNA-(cytosine-5) methyltransferase-PCNA complex as a target for p21WAF1. Science 277: 1996-2000.

Culhaci N, Sagol O, Karademir S, Astarcioglu H, et al. (2005). Expression of transforming growth factor-beta-1 and p27Kip1 in pancreatic adenocarcinomas: relation with cell-cycle-associated proteins and clinicopathologic characteristics. BMC Cancer 5: 98.

Espino PS, Pritchard S, Heng HH and Davie JR (2009). Genomic instability and histone H3 phosphorylation induction by the Ras-mitogen activated protein kinase pathway in pancreatic cancer cells. Int. J. Cancer 124: 562-567.

Gasparino E, Oliveira Neto AR, Del Vesco AP, Pires AV, et al. (2012). Expression of growth genes in response to glycerol use in Japanese quail diets. Genet. Mol. Res. 11: 3063-3068. 
Guo S, Liu M and Godwin AK (2012). Transcriptional regulation of hTREX84 in human cancer cells. PLoS One 7: e43610. Gysin S, Lee SH, Dean NM and McMahon M (2005). Pharmacologic inhibition of RAF $\rightarrow$ MEK $\rightarrow$ ERK signaling elicits pancreatic cancer cell cycle arrest through induced expression of p27Kip1. Cancer Res. 65: 4870-4880.

Hong SM, Omura N, Vincent A, Li A, et al. (2012). Genome-wide CpG island profiling of intraductal papillary mucinous neoplasms of the pancreas. Clin. Cancer Res. 18: 700-712.

Jackson-Grusby L, Beard C, Possemato R, Tudor M, et al. (2001). Loss of genomic methylation causes p53-dependent apoptosis and epigenetic deregulation. Nat. Genet. 27: 31-39.

Jiao L, Zhu J, Hassan MM, Evans DB, et al. (2007). K-ras mutation and p16 and preproenkephalin promoter hypermethylation in plasma DNA of pancreatic cancer patients: in relation to cigarette smoking. Pancreas 34: 55-62.

Kennedy AL, Adams PD and Morton JP (2011). Ras, PI3K/Akt and senescence: Paradoxes provide clues for pancreatic cancer therapy. Small GTPases 2: 264-267.

Kim JA, Hong S, Lee B, Hong JW, et al. (2007). The inhibition of T-cells proliferation by mouse mesenchymal stem cells through the induction of p16INK4A-cyclin D1/cdk4 and p21waf1, p27kip1-cyclin E/cdk2 pathways. Cell Immunol. 245: 16-23.

Lomberk G, Mathison AJ, Grzenda A and Urrutia R (2008). The sunset of somatic genetics and the dawn of epigenetics: a new frontier in pancreatic cancer research. Curr. Opin. Gastroenterol. 24: 597-602.

Ma J, Wang JD, Zhang WJ, Zou B, et al. (2010). Promoter hypermethylation and histone hypoacetylation contribute to pancreatic-duodenal homeobox 1 silencing in gastric cancer. Carcinogenesis 31: 1552-1560.

Missiaglia E, Donadelli M, Palmieri M, Crnogorac-Jurcevic T, et al. (2005). Growth delay of human pancreatic cancer cells by methylase inhibitor 5-aza-2'-deoxycytidine treatment is associated with activation of the interferon signalling pathway. Oncogene 24: 199-211.

Mostovich LA, Prudnikova TY, Kondratov AG, Loginova D, et al. (2011). Integrin alpha9 (ITGA9) expression and epigenetic silencing in human breast tumors. Cell Adh. Migr. 5: 395-401.

Omura N and Goggins M (2009). Epigenetics and epigenetic alterations in pancreatic cancer. Int. J. Clin. Exp. Pathol. 2: 310-326.

Pal-Bhadra M, Ramaiah MJ, Reddy TL, Krishnan A, et al. (2012). Plant HDAC inhibitor chrysin arrest cell growth and induce p21WAF1 by altering chromatin of STAT response element in A375 cells. BMC Cancer 12: 180 .

Pérez-Mancera PA, Rust AG, van der Weyden L, Kristiansen G, et al. (2012). The deubiquitinase USP9X suppresses pancreatic ductal adenocarcinoma. Nature 486: 266-270.

Primeau M, Gagnon J and Momparler RL (2003). Synergistic antineoplastic action of DNA methylation inhibitor 5-AZA2'-deoxycytidine and histone deacetylase inhibitor depsipeptide on human breast carcinoma cells. Int. J. Canc. 103: 177-184.

Rittenhouse DW, Talbott VA, Anklesaria Z, Brody JR, et al. (2011). Subject review: pancreatic ductal adenocarcinoma in the setting of mutations in the cystic fibrosis transmembrane conductance regulator gene: case report and review of the literature. J. Gastrointest. Surg. 15: 2284-2290.

Sato N, Fukushima N, Hruban RH and Goggins M (2008). CpG island methylation profile of pancreatic intraepithelial neoplasia. Mod. Pathol. 21: 238-244.

Scott SA, Dong WF, Ichinohasama R, Hirsch C, et al. (2006). '5-Aza-2'-deoxycytidine (decitabine) can relieve p21WAF1 repression in human acute myeloid leukemia by a mechanism involving release of histone deacetylase 1 (HDAC1) without requiring p21WAF1 promoter demethylation. Leuk Res. 30: 69-76.

Shin-Kang S, Ramsauer VP, Lightner J, Chakraborty K, et al. (2011). Tocotrienols inhibit AKT and ERK activation and suppress pancreatic cancer cell proliferation by suppressing the ErbB2 pathway. Free Radic. Biol. Med. 51: 1164-1174.

Takayama Y, Kokuryo T, Yokoyama Y, Nagino M, et al. (2008). MEK inhibitor enhances the inhibitory effect of imatinib on pancreatic cancer cell growth. Cancer Lett. 264: 241-249.

Tan HH and Porter AG (2009). p21(WAF1) negatively regulates DNMT1 expression in mammalian cells. Biochem. Biophys. Res. Commun. 382: 171-176.

Wallace EM, Lyssikatos JP, Yeh T, Winkler JD, et al. (2005). Progress towards therapeutic small molecule MEK inhibitors for use in cancer therapy. Curr. Top. Med. Chem. 5: 215-229.

Wang H, Zhao Y, Li L, McNutt MA, et al. (2008). An ATM- and Rad3-related (ATR) signaling pathway and a phosphorylation-acetylation cascade are involved in activation of p53/p21Waf1/Cip1 in response to 5-aza-2'deoxycytidine treatment. J. Biol. Chem. 283: 2564-2574.

Wang X, Sun DF, Lu R, Chen ZF, et al. (2009). RAF may induce cell proliferation through hypermethylation of tumor suppressor gene promoter in gastric epithelial cells. Cancer Sci. 100: 117-125.

Yu J, Walter K, Omura N, Hong SM, et al. (2012). Unlike pancreatic cancer cells pancreatic cancer associated fibroblasts display minimal gene induction after 5-aza-2'-deoxycytidine. PLoS One 7: e43456.

Zheng QH, Ma LW, Zhu WG, Zhang ZY, et al. (2006). p21Waf1/Cip1 plays a critical role in modulating senescence through changes of DNA methylation. J. Cell Biochem. 98: 1230-1248. 